\title{
EVALUATION OF PROSTATITIS IN AUTOPSIED PROSTATES: IS CHRONIC INFLAMMATION MORE ASSOCIATED WITH BPH OR CANCER?
}

\author{
Nicolas B Delongchamps ${ }^{1}$, Gustavo de la Roza ${ }^{2}$, Vishal Chandan ${ }^{2}$, Richard Jones ${ }^{1}$, Robert \\ Sunheimer ${ }^{2}$, Gregory Threatte ${ }^{2}$, Mary Jumbelic ${ }^{3}$, and Gabriel P Haas ${ }^{1}$ \\ 1 Department of Urology, SUNY Upstate Medical University, Syracuse, NY
}

2 Department of Pathology, SUNY Upstate Medical University, Syracuse, NY

3 Onondaga County Medical Examiner, Syracuse, $N Y$

\begin{abstract}
Purpose-Chronic inflammation $(\mathrm{CI})$ has been associated with prostate cancer and benign prostatic hyperplasia (BPH). However, the prevalence of $\mathrm{CI}$ in malignant and benign glands has never been compared. We evaluated the association between inflammation, BPH and cancer in autopsied prostates
\end{abstract}

Material and methods-We analysed prospectively 167 autopsied prostates. Pathological analysis identified each focus of cancer, BPH nodules and areas of acute (AI) or CI. Any cancer focus or BPH nodule involved directly with inflammation was recorded. The association between the prevalence of prostate cancer, BPH, and inflammation was statistically assessed.

Results-Inflammation was present in 113 (67.6\%) of 167 cases. CI was identified in 88 (53\%), $\mathrm{AI}$ in $6(4 \%)$ and both $\mathrm{CI}$ and $\mathrm{AI}$ in $19(11 \%)$ glands. In the majority of cases, inflammation was present in the transitional zone. 93 glands (56\%) were involved with BPH and $49(29 \%)$ with cancer. $75 \%$ of the glands harboring BPH were also involved with CI, as compared to only $50 \%$ of the glands without BPH ( $\mathrm{p}<0.01)$. Comparatively, the glands with and without any evidence of cancer were similarly involved with CI (55\% versus $58 \%, \mathrm{p}>0.1)$. Among the 27 glands involved with both cancer and $\mathrm{BPH}, \mathrm{CI}$ was more associated with $\mathrm{BPH}$ than cancer $(\mathrm{p}=0.006)$. AI was not significantly associated with either BPH or cancer.

Conclusions-CI was a common finding in autopsied prostates. It appeared to be directly associated with the presence of BPH, but not with cancer.

\section{Keywords}

Prostate cancer; Benign Prostatic Hyperplasia; chronic inflammation; autopsy

Correspondence: Gabriel P Haas, Department of Urology, SUNY Upstate Medical University, 750, East Adams Street, Syracuse, NY 13210, Tel: (315) 464 6106; Fax: (315) 464 6117; Email: haasg@upstate.edu.

This work has been presented as an abstract at the 2007 AUA meeting in Anaheim, CA.

Publisher's Disclaimer: This is a PDF file of an unedited manuscript that has been accepted for publication. As a service to our customers we are providing this early version of the manuscript. The manuscript will undergo copyediting, typesetting, and review of the resulting proof before it is published in its final citable form. Please note that during the production process errors may be discovered which could affect the content, and all legal disclaimers that apply to the journal pertain. 


\section{INTRODUCTION}

A better understanding of the natural history of prostate cancer may help to enhance its early detection and develop chemoprevention strategies. In this attempt, recent studies suggested a common relationship between inflammation and prostate cancer. This hypothesis was supported by the identification of some common molecular pathways in the development of both process 1 , as well by the possible association of prostate cancer with sexually transmitted infections ${ }^{2}$, anti-oxidant intake ${ }^{3}$ and oral anti-inflammatory drugs consumption. ${ }^{4}$ However, epidemiological studies are limited because an unknown proportion of chronic prostatic inflammation is not associated with any clinical sign or symptom. This type of inflammation, categorized by the National Institute of Health Consensus Classification into category IV prostatitis (asymptomatic inflammatory prostatitis), is an incidental pathological finding. Moreover, inflammatory infiltrates in prostate glands are heterogeneous in their nature, severity and location, suggesting the involvement of distinct molecular processes. Pathological studies are therefore more reliable than epidemiological studies to evaluate the association between inflammation and prostate cancer.

Areas of chronic inflammation are commonly identified in radical prostatectomy (RP) specimens 5 and prostate biopsies. ${ }^{6}$ However, there has not been to our knowledge any study comparing the prevalence of inflammation in benign and malignant prostate glands. The evaluation of inflammation in RP specimens is limited by the absence of control samples material, and the low cancer detection rate of prostate biopsies may not allow any comparison of inflammation between positive and negative biopsies.

We performed a large detection study on autopsied prostates at SUNY Upstate University, Syracuse, NY between August 2003 and October 2006. ${ }^{7}$ This study allowed the prospective collection of autopsied glands with and without any evidence of cancer. The presence and degree of inflammation and its spatial relationship with cancer and BPH was part of the histologic analysis in all samples. The association between inflammation, cancer and BPH was then statistically assessed.

\section{MATERIAL AND METHOD}

\section{Tissue collection}

We prospectively collected 210 consecutive prostate glands from deceased men, provided by the University Hospital, Syracuse, NY, the Onondaga County Medical Examiner, Syracuse, NY and by the National Disease Research Interchange, Philadelphia, PA. This study was approved by the Institutional Review Board and the tissue suppliers obtained informed consent from the next of kin. All samples were de-identified to protect the identity of the individual.

Age, race, and cause of death were recorded. The decedents had no known history of prostate cancer. At autopsy, the entire prostate gland together with the seminal vesicles, were excised and placed in 10 percent neutral buffered formalin. 43 specimen were unsatisfactory for evaluation because part of the gland was missing as a result of incomplete post-mortem resection. These subjects were excluded, leaving 167 prostate glands available for analysis.

\section{Whole Mount Prostate processing and histological evaluation}

After fixation for at least 72 hours, the glands were separated from the surrounding tissue, and their volume was measured. The glands were cut into 4 millimeters sections perpendicular to the posterior plane. The blocks obtained were labeled and embedded in paraffin, and then sectioned to produce 5-micrometers whole-mount sections that were stained with hematoxylin and eosin. A single pathologist (GdlR) analyzed the whole-mount sections. Each focus of cancer, BPH nodule and inflammatory infiltrate detected was outlined. The qualitative analysis 
of the inflammation was determined by the presence of only neutrophils in acute inflammation (AI), the presence of lymphocytes and/or plasma cells only in chronic inflammation (CI), and the presence of both type of inflammatory components in mixed inflammation (MI). The quantitative analysis of inflammation was determined by a grading system that was as follows: a) $1+$ when the inflammation was patchy and only present in the stroma; b) $2+$ when both glandular and stromal components were involved; and c) $3+$ when the infiltrates affected stroma and glands, but were also confluent, caused glandular destruction, or formation of abscesses. The location of inflammation was recorded in the transitional zone (TZ) or peripheral zone (PZ) according to the predominant amount of inflammatory infiltrates in the TZ or PZ. For the glands presenting an equal number of inflammatory infiltrates in the TZ and PZ, we considered the inflammation as diffuse. Inflammatory infiltrates were considered to be spatially associated with BPH nodules or cancer foci if they were observed either within or in the immediate periphery of them.

\section{Statistical analysis}

We distinguished different groups of prostate glands according to their pathological features: Glands with no evidence of BPH, cancer or inflammation; glands with cancer alone, BPH alone, and inflammation alone; glands with BPH and cancer, BPH and inflammation, cancer and inflammation; glands with cancer, BPH and inflammation all together. The association between inflammation, cancer and BPH was assessed using the chi square test for independent proportions and the McNemar test for correlated proportions. For statistical analysis, we considered grades $1+$ and $2+$ of inflammation as low-grade inflammation, and 3+ as high-grade. Statistical analyses were conducted using $\mathrm{p}<0.05$ as statistically significant.

\section{RESULTS}

The 167 prostate glands included in the study were from male subjects with a median age of 64 years (31-92). Of them, 27, 86 and 54 were under 50 years old, between 50 and 70 years old, and over 70 years old, respectively. The median gland volume was $40 \mathrm{~cm}^{3}(15-117)$.

Inflammatory infiltrates were detected in $113(68 \%)$ glands. Table 1 shows their pathological characteristics. CI alone was present in $88(53 \%)$ glands, AI alone in $6(4 \%)$ glands and both $\mathrm{CI}$ and $\mathrm{AI}$ in $19(11 \%)$. The prevalence of $\mathrm{CI}$ was not significantly different in large $(\geq 40$ $\left.\mathrm{cm}^{3}\right)$ and small glands $\left(<40 \mathrm{~cm}^{3}\right)(69 \%$ versus $56 \%, \mathrm{p}=0.1)$. AI infiltrates were more frequently peri or intra-glandular $(96 \%)$. AI was high-grade in $48 \%$ of the cases whereas CI was highgrade in only $13 \%$. The majority of inflammatory infiltrates were located in the TZ. Infiltrates of CI were observed only in the PZ in 15 glands, whereas infiltrates of AI were not seen in the $\mathrm{PZ}$ alone in any case (Table 1).

Ninety-three glands (56\%) were involved with BPH and 49 (29\%) with cancer. Among them, 27 were involved with both BPH and cancer. The cancers detected in glands harboring BPH had similar pathological features than those detected in glands without BPH. The majority of them were organ confined (88\%) and had a Gleason score of 6 or less (70\%) (Table 2).

Table 3 shows the prevalence of $\mathrm{CI}$ and $\mathrm{AI}$ in the prostate glands with cancer, $\mathrm{BPH}$, both cancer and BPH, and in the glands with no evidence of BPH or cancer. $75 \%$ (70/93) of the glands harboring BPH were also involved with CI, as compared to only 50\% (37/74) of the glands without BPH $(\mathrm{p}<0.01)$. Comparatively, the glands with and without any evidence of cancer were similarly involved with $\mathrm{CI}(55 \%$ versus $58 \%, \mathrm{p}>0.1)$. The prevalence of $\mathrm{CI}$ in glands with $\mathrm{BPH}$ and without cancer was 79\% (52/66). Comparatively, CI prevalence was $41 \%(9 / 22)$ in glands with cancer and without $\mathrm{BPH}(\mathrm{P}<0.001)$. In glands with no evidence of cancer or $\mathrm{BPH}$, the prevalence of $\mathrm{CI}$ was $54 \%$. When performing the statistical analysis by age groups, we found similar results in men between 50 and 70 years old, and in men over 70 years old, as 
compared to the entire cohort. However, no statistical difference between the prevalence of CI in glands with BPH and cancer was found in men under 50 years old (Table 4).

The prevalence of AI was low and was not statistically different between any of the groups $(\mathrm{p} \approx 1)$. Among the 9 glands involved with both cancer and CI, inflammatory infiltrates were located inside or in the periphery of tumor foci in 4 (44\%). Comparatively, in the 52 glands involved with both $\mathrm{BPH}$ and $\mathrm{CI}$, inflammatory infiltrates were located inside BPH nodules or in their periphery in $44(85 \%)(\mathrm{p}<0.01)$. Among the 27 glands involved with both cancer and $\mathrm{BPH}, 18$ contained areas of CI (Table 3). Of these cases, CI was located inside or in the periphery of BPH nodules only in 11, of cancer foci only in 1 , of both BPH nodules and cancer foci in 3 , and of neither of them in 3 , respectively $(\mathrm{p}=0.006)$.

There was no significant difference in the degree of CI between glands with cancer alone, BPH alone, BPH and cancer together and glands with neither of them (Table 5). CI infiltrates were more frequently stromal in glands with BPH alone and glands with cancer alone, whereas it was more frequently peri and/or intra-glandular in glands with either BPH and cancer together or glands without $\mathrm{BPH}$ or cancer (Table 5). However, the difference was statistically significant only between glands with BPH alone and glands with BPH and cancer $(\mathrm{p}=0.049)$ and between glands with BPH alone and glands without BPH or cancer $(\mathrm{p}=0.025)$.

\section{DISCUSSION}

CI has emerged as a potential risk factor for carcinoma in many organs such as the liver, colon, bladder, lung and pancreas. ${ }^{8,9}$ The high prevalence of $\mathrm{CI}$ infiltrates in pathological specimens of the prostate, including RP specimens, prostate biopsies and TURP chips, has led to speculation that chronic inflammation may also be associated with prostate cancer. This hypothesis was supported by the implication of common molecular pathways in both processes. Some authors observed an increased expression of COX-2 in prostate cancer in comparison with benign tissue, this enzyme being implicated in the prostaglandin synthesis pathway. ${ }^{10}$ Others observed that prostate cancer cells were producing high amounts of MCP-1, a chemotactic protein playing a key role in the recruitment and activation of monocytes during inflammation. ${ }^{1}$ Moreover, several genes implicated in the immunological response, such as RNASEL ${ }^{11}$, MSR 12 or MIC-1 13 , are located in regions that have been linked to familial prostate cancers. The association between prostate cancer and CI was also evaluated on pathological material. Some authors investigated the association and the influence of CI on prostate cancer development by performing repeated biopsies in 177 patients with a high PSA level $\left(4 \mathrm{ng} / \mathrm{mL}\right.$ or greater) and/or an abnormal digital rectal examination. ${ }^{6}$ Of them, 144 (81\%) had CI on initial biopsies and $39(22 \%)$ had cancer. Of the 39 patients with cancer, 29 showed also CI on biopsies. All the patients underwent a 5-year follow up and subsequent biopsies were performed in 84 patients. The authors reported 29 new cancers diagnosed in the 144 patients who had CI in the initial biopsies, representing a new cancer incidence of $20 \%$ in this subset. Comparatively, only 2 new cancers were subsequently discovered in the subset of 33 patients who were not found to have $\mathrm{CI}$ in the initial biopsies, representing only a $6 \%$ incidence of new cancer. The authors concluded that there was a strong association between CI and prostate cancer. However, clinical studies are limited by verification bias because many prostate cancers are latent and undetected through PSA screening. ${ }^{14,15}$ Additionally, using a PSA cutoff for biopsy creates another potential bias since prostatitis increases PSA value. Prostate biopsies have a low sensitivity for cancer detection and in this study only $48 \%$ of the patients underwent subsequent biopsies during follow up. Of the 33 patients with no inflammation on the initial biopsies, only 7 underwent repeated biopsy. The 2 patients newly diagnosed with cancer in this subgroup were therefore not representing a $6 \%$ incidence of cancer but more objectively 29\% (2/7). Another limitation related to the use of prostate biopsies is their poor spatial correlation with whole mount analysis. In the study from MacLennan et al 
6 , cancer and inflammation coexisted in separate biopsy cores in the majority of the cases, corresponding therefore to distinct locations in the glands.

Other pathological studies on RP specimen failed to demonstrate any clear association between chronic inflammation and prostate cancer. Gerstenbluth et al ${ }^{5}$ examined 40 whole mount RP specimens for the presence and distribution of $\mathrm{CI}$ infiltrates. All the specimens contained multifocal areas of $\mathrm{CI}$, that were located in the $\mathrm{PZ}$ in $95 \%$ and in the $\mathrm{TZ}$ in $87.5 \%$ of the cases. Inflammatory infiltrates were spatially associated with cancer in only half of the RP specimens. In comparison, $\mathrm{CI}$ was noted within areas of BPH in all the cases with $\mathrm{CI}$ in the $\mathrm{TZ}$ and in $82.5 \%$ of all the cases together. The authors concluded that CI was more associated with BPH than cancer on RP specimens.

However, there has not been to our knowledge any pathological study using control material. Autopsied prostates gave us the opportunity to evaluate the prevalence of CI in a control group of prostate glands with no evidence of cancer or BPH. Our findings confirmed the ubiquitous nature of CI in all the prostate glands. However, $\mathrm{CI}$ was significantly more prevalent in glands with $\mathrm{BPH}$ as compared to glands with no BPH or glands with cancer. The prevalence of CI was not associated with that of prostate cancer. Even in glands with both cancer and CI, infiltrates of inflammation were not identified within or in the periphery of tumor foci. CI was, in contrast, significantly associated spatially with BPH nodules. These results are consistent with the findings of others. Irani et al ${ }^{16}$ found indeed that malignant tissue was significantly less involved in high-grade inflammation than benign adjacent tissue. Prostate cancer may fail to provide the signals necessary to activate the inflammatory mechanism ${ }^{17}$, providing therefore an escape mechanism from immune detection. However, in the same study, Irani et al ${ }^{16}$ found that patients with high-grade inflammation surrounding malignant glands in RP specimens had significantly more postoperative biochemical recurrence than patients with lowgrade inflammation. Inflammation is complex in its nature and probably involves variable and concomitant mechanisms that cannot be distinguished by studying inflammatory infiltrates on pathological material.

This study has several limitations. First, we did not quantify the extent of inflammation within each prostate specimen and we distinguished only 2 distinct grades of severity. Our classification was therefore less detailed than that proposed by Nickel et al ${ }^{18}$ in 2001 in an attempt to reach a consensus. Second, we did not report the presence of other prostatic lesions such as high-grade PIN, post-atrophic hyperplasia or proliferative inflammatory atrophy (PIA). There is accumulating evidence that these lesions may be precursors to prostate cancer. PIA lesions are often located near activated inflammatory cells, as well as adjacent to PIN lesions and to prostatic carcinomas. ${ }^{19}$ The presence of such lesions in our autopsied prostates could have affected our results. Finally, an important limitation of most autopsy studies is that a detailed history can not be obtained from the subjects, and therefore we do not know what proportion of our study population may have experienced clinical evidence of acute or chronic prostatitis prior to death.

\section{CONCLUSION}

In conclusion, CI infiltrates were commonly identified in autopsy prostates, irrespectively of the presence of cancer. The prevalence and location of CI were significantly associated with that of BPH. In contrast, we did not find a significant association between $\mathrm{CI}$ and prostate cancer.

\section{Acknowledgements}

Supported by NIH grants AG021389 and CA097751. 


\section{ABBREVIATIONS}

\section{BPH}

benign prostatic hyperplasia

CI

chronic inflammation

AI

acute inflammation

MI

mixed inflammation

RP

radical prostatectomy

TZ

tranzitional zone

PZ

peripheral zone

\section{References}

1. Lu Y, Cai Z, Galson DL, Xiao G, Liu Y, George DE, et al. Monocyte chemotactic protein-1 (MCP-1) acts as a paracrine and autocrine factor for prostate cancer growth and invasion. Prostate 2006;66:1311-8. [PubMed: 16705739]

2. Dennis LK, Dawson DV. Meta-analysis of measures of sexual activity and prostate cancer. Epidemiology 2002;13:72-9. [PubMed: 11805589]

3. Clark LC, Dalkin B, Krongrad A, Turnbull BW, Slate EH, Witherington R, et al. Decreased incidence of prostate cancer with selenium supplementation: results of a double-blind cancer prevention trial. Br J Urol 1998;81:730-4. [PubMed: 9634050]

4. Perron L, Bairati I, Moore L, Meyer F. Dosage, duration and timing of nonsteroidal anti-inflammatory drug use and the risk of prostate cancer. Int J Cancer 2003;106:409-15. [PubMed: 12845682]

5. Gerstenbluth RE, Seftel AD, MacLennan GT, Rao RN, Corty EW, Ferguson K, et al. Distribution of chronic prostatitis in radical prostatectomy specimens with up-regulation of $\mathrm{Bcl}-2$ in areas of inflammation. J Urol 2002;167:2267-70. [PubMed: 11956490]

6. MacLennan GT, Eisenberg R, Fleshman RL, Taylor M, Fu P, Resnick MI, et al. The influence of chronic inflammation in prostatic carcinogenesis: A 5-year followup study. J Urol 2006;176:1012-6. [PubMed: 16890681]

7. Haas GP, Delongchamps NB, Jones RF, Chandan V, Serio AM, Vickers AJ, et al. Needle biopsies on autopsy prostates: Sensitivity of cancer detection based on true prevalence. J Natl Cancer Inst 2007;99:1484-9. [PubMed: 17895474]

8. Coussens LM, Werb Z. Inflammation and cancer. Nature 2002;420:860. [PubMed: 12490959]

9. Hussain SP, Hofseth LJ, Harris CC. Radical causes of cancer. Nat Rev Cancer 2003;3:276. [PubMed: 12671666]

10. Hussain T, Gupta S, Mukhtar H. Cyclooxygenase-2 and prostate carcinogenesis. Cancer lett 2003;191:125-35. [PubMed: 12618325]

11. Casey G, Neville PJ, Plummer SJ, Xiang Y, Krumroy LM, Klein EA, et al. RNASEL Arg462Gln variant is implicated in up to $13 \%$ of prostate cancer cases. Nat Genet 2002;32:581-3. [PubMed: 12415269]

12. Xu J, Zheng SL, Komiya A, Mychaleckyj JC, Isaacs SD, Hu JJ, et al. Germline mutations and sequence variants of the macrophage scavenger receptor 1 gene are associated with prostate cancer risk. Nat Genet 2002;32:321-5. [PubMed: 12244320] 
13. Nakamura T, Scorilas A, Stephan C, Yousef GM, Kristiansen G, Jung K, et al. Quantitative analysis of macrophage inhibitory cytokine-1 (MIC-1) gene expression in human prostatic tissues. Br J Cancer 2003;88:1101-4. [PubMed: 12671711]

14. Punglia RS, D’Amico AV, Catalona WJ, Roehl KA, Kuntz KM. Effect of verification bias on screening for prostate cancer by measurement of prostate-specific antigen. N Engl J Med 2003;349:335-42. [PubMed: 12878740]

15. Thomson IM, Pauler DK, Goodman PJ, Tangen CM, Lucia MS, Parnes HL, et al. Prevalence of prostate cancer among men with a prostate-specific antigen level $<$ or $=4 \mathrm{ng}$ per milliliter. $\mathrm{N}$ Engl $\mathrm{J}$ Med 2004;350:2239-46. [PubMed: 15163773]

16. Irani J, Goujon JM, Ragni E, Peyrat L, Hubert J, Saint F, et al. High-grade inflammation in prostate cancer as a prognostic factor for biochemical recurrence after radical prostatectomy. Urology 1999;54:467-472. [PubMed: 10475356]

17. Troy A, Davidson P, Atkinson C, Hart D. Phenotypic characterisation of the dendritic cell infiltrate in prostate cancer. J Urol 1998;160:214. [PubMed: 9628653]

18. Nickel JC, True LD, Krieger JN, Berger RE, Boag AH, Young ID. Concensus development of a histopathological classification system for chronic prostatic inflammation. BJU Int 2001;87:797805. [PubMed: 11412216]

19. Nelson WG, De Marzo AM, DeWeese TL, Isaacs WB. The role of inflammation in the pathogenesis of prostate cancer. J Urol 2004;172:S6-S12. [PubMed: 15535435] 
Table 1

Pathological features of chronic and acute inflammation in 113 prostate glands:

\begin{tabular}{|c|c|c|}
\hline & Chronic inflammation $(n=107)$ & Acute inflammation $(n=25)$ \\
\hline \multicolumn{3}{|l|}{ Histological location: } \\
\hline Stromal only & $50(47 \%)$ & $1(4 \%)$ \\
\hline Peri and/or intra-glandular & $57(53 \%)$ & $24(96 \%)$ \\
\hline \multicolumn{3}{|l|}{ Degree: } \\
\hline Low-grade & $93(87 \%)$ & $13(52 \%)$ \\
\hline High-grade & $14(13 \%)$ & $12(48 \%)$ \\
\hline \multicolumn{3}{|l|}{ Anatomical location: } \\
\hline $\mathrm{PZ}$ & $15(14 \%)$ & 0 \\
\hline $\mathrm{TZ}$ & $41(38 \%)$ & $11(44 \%)$ \\
\hline Both PZ and TZ & $51(48 \%)$ & $14(56 \%)$ \\
\hline
\end{tabular}


Table 2

Pathological characteristics of the 49 prostate cancers identified

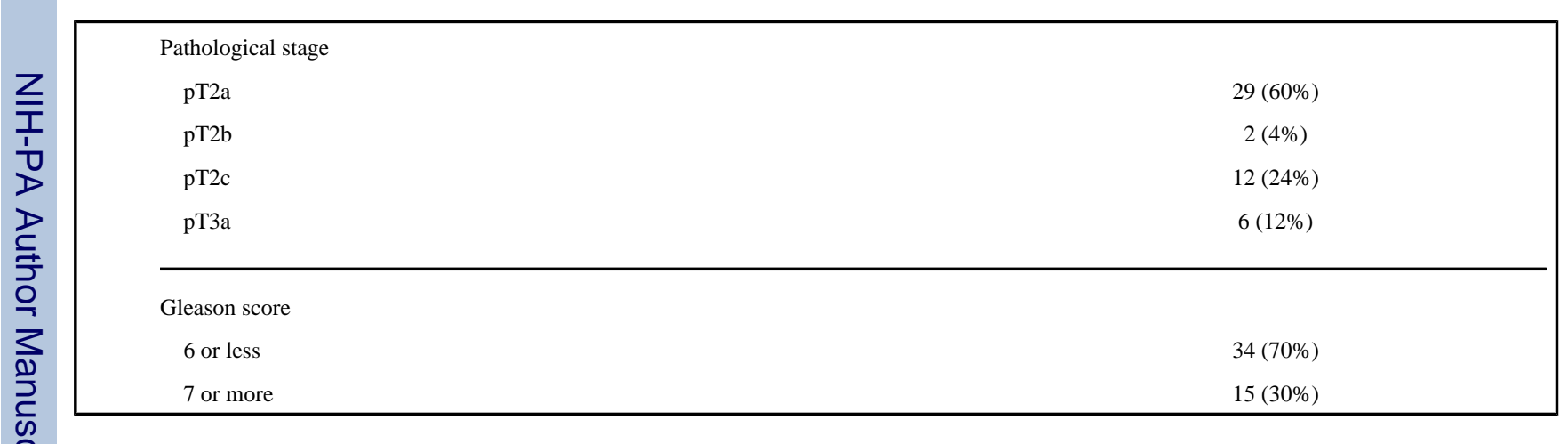


Table 4

Prevalence of CI by age groups in glands with BPH alone and cancer alone

\begin{tabular}{|r|l|l|l|}
\hline & BPH alone & Cancer alone & P value \\
\hline All cohort $(\mathrm{n}=167)$ & $52 / 66(79 \%)$ & $9 / 22(41 \%)$ & $<0.001$ \\
\hline Men $<50$ years old $(\mathrm{n}=27)$ & $5 / 7(71 \%)$ & $0 / 1(0 \%)$ & 0.16 \\
\hline Men between 50 and 70 $(\mathrm{n}=86)$ & $31 / 39(79 \%)$ & $3 / 7(43 \%)$ & 0.04 \\
\hline Men $>70$ years old $(\mathrm{n}=54)$ & $16 / 20(80 \%)$ & $5 / 13(38 \%)$ & 0.01 \\
\hline
\end{tabular}




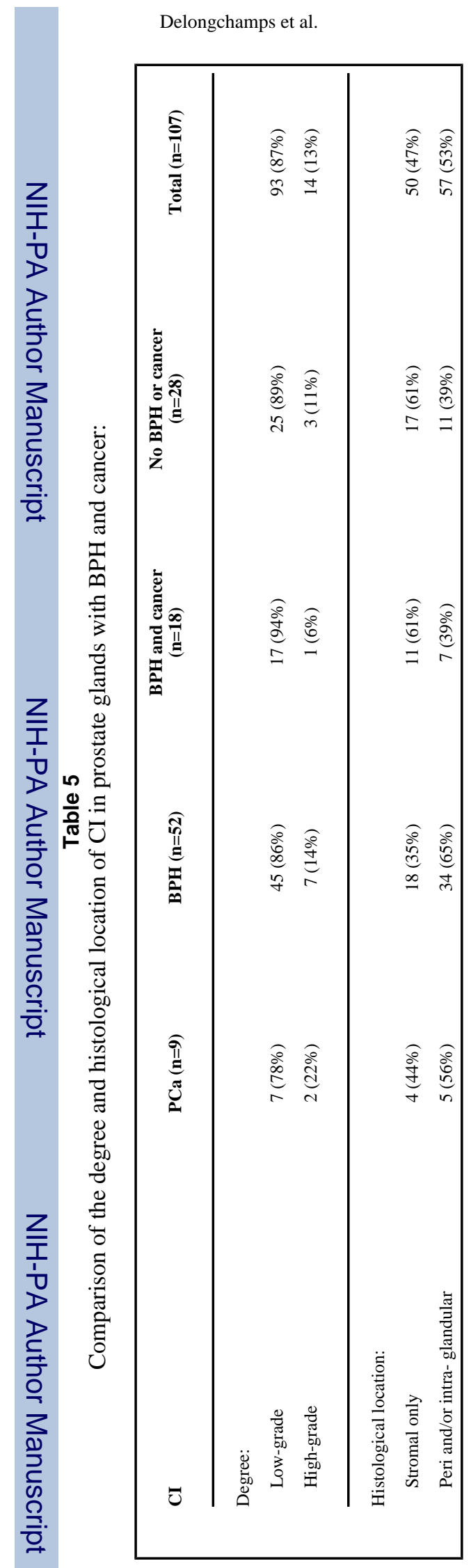

J Urol. Author manuscript; available in PMC 2009 May 1. 